\title{
Arbor
}

\section{Los Servicios de Inteligencia en la Transición}

\author{
Juan María de Peñaranda y Algar
}

Arbor CLXXX, 709 (Enero 2005), 99-119 pp.

En el desarrollo de nuestra Transición política tuvieron un importante protagonismo los Servicios de Información españoles. Entre ellos, los mejor considerados como de "Inteligencia" eran los vinculados, durante aquellos años, a la Presidencia del Gobierno en la persona de su Presidente: la Tercera Sección del Alto Estado Mayor (AEM), la Organización Contrasubversiva Nacional (OCN) y el Servicio Central de Documentación (SECED).

El presente artículo se refiere al periodo comprendido entre los años 1968 en que se monta la Organización "Conde»-germen de la OCN-y 1977 en que terminan su vida oficial la Tercera Sección AEM y el SECED para constituir conjuntamente el nuevo Centro Superior de Información de la Defensa (CESID) que dispondría ya de todos los elementos necesarios para ser homologable con otros servicios extranjeros de Inteligencia.

En esa etapa los referidos Servicios llevaron a cabo una delicada actividad secreta dentro y fuera de España, en el amplio marco de los diversos sectores de la Administración, la Política, la Empresa, la Cultura y la Sociedad en general, tarea que facilitó el tránsito desde el Régimen autoritario del General Franco a la Monarquía parlamentaria encarnada por Don Juan Carlos I, tratando de lograr que esa difícil Transición pudiera desenvolverse en un clima de comprensión política y tranquilidad ciudadana hasta la celebración de las primeras elecciones generales al Congreso de los Diputados y al Senado.

Aunque desde un punto de vista meramente político alguien pudiera calificar ese decenio de "pre-transición", al tratar de los Servicios de Inteligencia tal fase constituye realmente la verdadera Transición: el mejor sustento al tránsito político y, al mismo tiempo, el imprescindible proceso para la cristalización de un instrumento fundamental en beneficio directo del Estado. 


\section{Preámbulo}

Antes de entrar en el tema en cuestión parece conveniente dar unas pinceladas sobre lo que entendemos por ambos términos de la proposición -Servicios de Inteligencia y Transición- elementos discutibles y discutidos. Nuestro criterio personal, se apoya en la experiencia de muchos especialistas con largos años de profesionalidad.

\subsection{Los Servicios de Inteligencia en España}

Es bien conocido que durante décadas varios ministerios contaron, para cubrir sus propias necesidades, con algún órgano de información. En Asuntos Exteriores, Información y Turismo, Relaciones Sindicales y otros ministerios existían oficinas dedicadas a la adquisición y producción de información, cuya labor de análisis y evaluación no solía superar la inmediatez de respuesta que les exigían los propios fines departamentales. Pero en ningún caso podían ser consideradas tales estructuras como Servicios de Información.

Por su parte, los tres ministerios militares entonces existentes (Ejército, Marina y Aire) venían dedicando desde mucho tiempo atrás un importante esfuerzo y medios a atender las necesidades de información militar que exigía el cumplimiento de las misiones encomendadas a sus Ejércitos. En cada uno de ellos funcionaba una Segunda Sección (Información) integrada en su Estado Mayor, que se servía de una red interior (Segunda-Bis) desplegada por Capitanías y Unidades, y de otra exterior constituida por las Agregadurías Militares, Navales ó Aéreas en el extranjero. El conjunto articulado de tales órganos recibía la denominación habitual de Servicio de Información del respectivo Ejército.

Del mismo modo, el ministerio de la Gobernación -más adelante, Interior- contaba con dos Servicios para apoyar sus responsabilidades de seguridad y orden público: el Servicio de Información de la Guardia Civil, inserto en el Estado Mayor de esa Dirección, y la Jefatura de Información -después Comisaría General- integrada en la Dirección General de Seguridad. En aquellos años la Inspección General de la Policía Armada contaba asimismo con un reducido órgano informativo para su propio uso. Pues bien, estos Servicios de Información disponían -como los militares- de importantes medios para cubrir las demandas de sus Departamentos ministeriales, desarrollando una adecuada labor de obtención, investigación y evaluación de las noticias y datos recogidos. Pero ni 
unos ni otros -si bien cubrían todo el espacio geográfico nacional- podían ser reputados como Servicios de Inteligencia, al menos tal como pretendemos encuadrarlos en el presente artículo.

Sin embargo el Servicio de Información del Alto Estado Mayor -su Tercera Sección-cumplía misiones de nivel estatal, dentro y fuera de España, en consonancia con otros servicios extranjeros calificados vulgarmente como de espionaje. Dicho alto centro proporcionaba a la Jefatura del Estado y a la Presidencia del Gobierno, información clave de muy diverso tipo y procedencia, para la toma de sus decisiones, tal como ha desarrollado el autor del anterior capítulo. Aquella Tercera Sección producía lo que vino en llamarse en países anglófonos «inteligencia», para cuya difusión a la Superioridad era exigible la previa evaluación y el contraste riguroso con otras informaciones y fuentes, manteniendo naturalmente su actuación en secreto.

En el otoño de 1968 nace en el Alto Estado Mayor, la Organización «Conde» precedente inmediato de la Organización Contrasubversiva Nacional (OCN), con el expreso objetivo de afrontar el duro reto del estudio y la lucha contra incipientes actividades subversivas en el país; y en marzo de 1972 se crea oficialmente en Presidencia del Gobierno el Servicio Central de Documentación (SECED) que vendría a dar cobertura pública y a desarrollar las posibilidades y capacidades de la OCN, apareciendo ya como un Servicio de Inteligencia, si bien limitado al campo de la información interior.

Ambos Servicios -Tercera Sección y SECED- serían prácticamente fusionados en misiones y medios en 1977, dando origen al Centro Superior de Información de la Defensa (CESID), ya un completo y verdadero Servicio. De tales componentes tratará este breve estudio: ellos son los que en la etapa que pretendemos describir merecen el apelativo de «Inteligencia" por su carácter nacional y dependencia del Presidente del Gobierno.

\subsection{La transición política}

El marco de estudio del presente artículo tiene su inicio a finales de 1968 con la puesta en marcha de la citada Organización CONDE por indicación personal del Generalísimo Franco, y cabría acordar que esa etapa predemocrática concluía con la celebración de las primeras elecciones generales, el 15 de junio de 1977. Esa década (1968-77) es de atención indispensable al profundizar en la labor de los Servicios de Inteligencia du- 
rante la Transición, ya que, en buena medida, fue entonces cuando se hizo viable -con el concurso de variados esfuerzos nacionales- aquel tránsito político en paz y orden, tanto durante los años que sucedieron al fallecimiento del Jefe del Estado como en los que le habían precedido.

Si el marco mínimo de la Transición queda limitado por la fecha del 20 de diciembre de 1975 en que producía el «cumplimiento de las previsiones sucesorias», y el referéndum de la Reforma Política de 12 de diciembre de 1976, resulta a nuestro juicio indispensable retroceder hasta la fecha del asesinato del Almirante Carrero (20.12.73) e incluso hasta aquella en la que SAR Don Juan Carlos de Borbón era designado sucesor en la Jefatura del Estado, a título de Rey (22.7.69). Llegar atrás hasta octubre de 1968 es muy útil para el estudio a fondo de la Transición, aunque aún no había trascendido al ciudadano de a pié la noción de tránsito político, ni los pasos firmes -a veces inciertos- que conducirían a aqué lla. De ahí que no consideremos oportuno seguir la pauta de la mayor parte de los libros publicados en los que se fija el comienzo de la Transición en la Jornada electoral de junio del 77, ni mucho menos en la proclamación de la Constitución Española, el 6 de diciembre de 1978. Lo que resultaría aceptable para un estudio de carácter sociológico o político, no lo es en absoluto al tratar los Servicios de Inteligencia. Todo lo que vendría después -incluída la creación del CESID- se fraguó, lenta pero irreversiblemente, a lo largo de aquella década.

Cabría incluir en el presente capítulo dedicado a «los Servicios de Inteligencia en la Transición» la andadura inicial del CESID, creado el 4 de julio de 1977 aún en periodo preconstitucional; pero ha parecido más útil desde un punto de vista de la adecuada articulación del libro, dedicar a ese Centro Superior un capítulo específico en el que compendiar sus veinticinco años de vida.

\section{La Tercera Sección del Alto Estado Mayor}

\subsection{El inicio de su decadencia}

En el artículo anterior «El periodo predemocrático de los Servicios de Inteligencia»- han sido recogido los pormenores del encomiable funciona miento de la Tercera Sección del AEM durante las primeras tres décadas de su existencia, a lo largo de las cuales sufrió varias reorganizaciones en su estructura y en sus prioridades, prestando la mayor atención a las necesi dades informativas que el Estado le reclamaba en cada circunstancia. 


\section{Los Servicios de Inteligencia en la Transición}

El Alto Estado Mayor atravesó diversas etapas con reconocido prestigio en instituciones públicas y privadas por su destacada intervención en cues tiones de carácter estratégico, ya fuera militar, económico o informativo. Pero el fin de la autarquía había reducido su influencia política; y, años des pués, el cese del TG. Muñoz Grandes en su función de Vicepresidente del Gobierno (22.7.67) representaría un significativo punto de inflexión en aquella influencia, al quedar el «Alto» más alejado de las esferas de poder. Se estaba agotando el ciclo vital de un organismo tanto tiempo considerado como Cuartel General del Generalísimo. Se trataba de una decisión política sin retorno que produciría penosos efectos en el funcionamiento del alto centro militar: recortes en sus tareas de información y crecientes dificultades para hacerse oír y para acceder a los indispensables recursos humanos y económicos con los que atender sus cometidos.

Tras el asesinato del Almirante Carrero, los dos Vicepresidentes militares que le sucedieron (TG,s Santiago y Gutiérrez Mellado) hicieron patente su preeminencia sobre los Jefes del AEM (TG,s Díez-Alegría y Fernández Vallespín), que vieron recortadas sus capacidades y filtradas sus pretensiones.

El Alto Estado Mayor pudo haber luchado para afrontar esa crisis de prestigio e influencia en los asuntos de Estado; pero el cambio que se avecinaba era imparable. España estaba buscando el rumbo que le acercase al resto de los países occidentales. El propio TG Díez-Alegría aportaba un planteamiento diferente al tradicional del «Alto» en décadas precedentes: un estilo nuevo de estudio y coordinación más que de control y ejecución de actividades, algunas de las cuales se salían de lo puramente militar. $\mathrm{Su}$ voz fue desatendida en determinadas esferas gubernamentales, políticas y castrenses.

Todas esas dificultades se transfirieron íntegras a la Tercera Sección, que padeció años difíciles. Reunía una magnífica panoplia de profesionales con muchos años de servicio y especialidad, pero sus aspiraciones se veían aplazadas -cuando no preteridas- por otras necesidades nacionales priori tarias, entre ellas la aparición impetuosa de los Servicios que se vincularían a Presidencia. Años más tarde todo quedaría resuelto con una boda forzada entre ambas «Inteligencias», de la que todos se felicitarían después.

\subsection{La vigencia de sus misiones}

La Tercera Sección continuó desarrollando sus amistosas y fructíferas relaciones con los Servicios occidentales aunque la apertura diplomática 
y comercial de España con el resto del mundo parecía hacer innecesarias, negociaciones que en décadas anteriores llevaban los Servicios de Inteligencia; en cualquier caso, facilitó durante la Transición contactos indispensables con otras naciones e incluso, gestionó asuntos que le solicitaba el SECED, pues este Servicio que no tenía actividad exterior. La «Tercera” siguió produciendo beneficios al Estado con sus prestigiadas tareas de espionaje y contraespionaje, si bien reorientando su tradicional trabajo en áreas africanas y asuntos del exilio hacia otros temas compartidos con nuestros amigos y aliados, y dando mayor énfasis y atención a los países comunistas y a su acción subversiva en el mundo, de modo que parte de los especialistas y agentes de la Sección volcaron también su esfuerzo en el seguimiento, en el exterior, de individuos ligados a movimientos desestabilizadores, tales como grupos marxistas, separatistas, terroristas, etc..., aunque sin entrar en cometidos de orden público y represión que tenía excluidos y que quedaban a cargo de los Cuerpos y órganos de Seguridad, adscritos al Ministerio de la Gobernación.

Sin embargo, en la denominada IV etapa del Alto Estado Mayor, iniciada en 1968, la Tercera Sección, por medio de su Negociado de Interior, se ocupaba del estudio y seguimiento de una subversión aún incipiente o al menos poco activada y clandestina. De dicho Negociado saldría el «equipo San Martín» que constituiría la Organización «Conde», y que pasados dos años daría lugar a la Organización Contrasubversiva Nacional $(\mathrm{OCN})$ de la que trataremos más adelante, con lo que la Tercera Sección vio también disminuido su campo de actividad con la definitiva pérdida de competencia en la lucha contra la subversión, en un momento delicado y crucial de la vida nacional.

La «Tercera» refugió su protagonismo en el intento de coordinar los Servicios de Información de los Ejércitos. Pero, si en décadas anteriores los Cuarteles Generales habían aceptado de buen grado las órdenes e indicaciones del Alto Estado Mayor, ahora sus Estados Mayores, muy celosos de la labor de sus Segundas Secciones, rechazaban más o menos solapadamente la intervención de "Vitruvio» -habitual referencia a la sede del «Alto»- en asuntos que entendían de su propia competencia. Así que la conveniente coordinación de toda la información militar quedó en los papeles, como un buen deseo sin aplicación por el momento. La creación de la Junta de Jefes de Estado Mayor -primero con carácter secreto, más adelante publicada en Boletín Oficial- facilitó la continuación de los trabajos, pero el montaje de un Centro de Información de las Fuerzas Armadas (CIFAS), tanto tiempo anhelado y discutido, quedaría aún pendiente sobre la mesa muchos años. Algo similar acontecería a una 


\section{Los Servicios de Inteligencia en la Transición}

«Comisión de información especial», - -que el «Alto» no llegó a sacar adelante en aquellos años- para coordinar diversos órganos de la Administración.

Algunos especialistas consideran que tan variadas circunstancias afectaron al peso específico de la Tercera Sección y, en alguna medida, al entusiasmo de sus Oficiales, a la plantilla de sus especialistas y al volumen de sus presupuestos; y ya se sabe que en un Servicio de Información el recorte en asignaciones de personal y en dotaciones extraordinarias y fondos reservados es el principio del fin. Su estructura territorial iba anquilosándose en cometidos y medios, pudiendo dar la imagen de meras oficinas burocráticas. Pero por fortuna, entre 1997 y 1999, algunas de sus más relevantes especialidades -espionaje, contraespionaje, criptografía, escucha radio-telegráfica y telefónica, etc..- se concentrarían con el SECED para dar vida al CESID, Servicio de Inteligencia que contaría así con todas las áreas indispensables.

\section{La Organización Contrasubversiva Nacional (OCN)}

\subsection{La Organización "Conde» (1968-1969)}

La razón de su creación en septiembre de 1968 hay que buscarla en una decisión del Generalísimo en aquel verano al comprobar la necesidad de estudiar en profundidad la subversión que surgía con fuerza en el ámbito universitario, sin que las autoridades académicas y ministeriales hallasen entonces medio de reducirla. Con tal motivo el titular de Educación y Ciencia, Villar Palasí, solicitaba ayuda al Teniente General Muñoz Grandes, Jefe del Alto Estado Mayor, quien ordenó la inmediata selección de un reducido equipo de Oficiales del Subnegociado de Interior, de la Tercera Sección, que se dedicase en exclusiva y con el mayor interés al seguimiento de aquella amenaza interior. El Mando decidió así encomendar la constitución del equipo al Comandante San Martín, al que se dio potestad para elegir, a quienes habían de integrar la que tomaría el nombre de Organización "Conde», nombre clave que se adjudicaba a su Jefe, en el AEM.

Este órgano clandestino quedó constituido inicialmente por el «Gabinete de Enlace con el Sr. Ministerio de Educación y Ciencia», en permanente contacto con el Subsecretario Monreal. El equipo redactó su propio plan de acción, denominado "Canadá», que obtendría la aprobación superior del Vicepresidente del Gobierno el 25 de octubre, y se impulsaría 
en enero de 1969, y cuya finalidad primordial era ganar la opinión estudiantil, a favor de la reforma universitaria en marcha, alejando a la juventud del contagio de movimientos subversivos. La creciente aparición de revueltas estudiantiles, con un grado de conflictividad, intoxicación e interrelación no conocido antes, obligaba a buscar los orígenes de tales movimientos y a estudiar el diseño de medidas que permitieran hacerles frente, una vez identificados. Más adelante se comprobaría la necesidad de crear una herramienta secreta de mayor entidad -la OCN- que pudiera atender también a la interpretación y seguimiento de otros focos conflictivos que empezaban a surgir en España.

Las nuevas circunstancias aconsejaron desligar la Organización «Conde» de la inicial tutela de la Tercera Sección del AEM, e instalarla independientemente en un pequeño chalet de la Colonia de la Prosperidad al nordeste de Madrid, que pronto sería - por insuficiente- trasladada a un inmueble más amplio y adecuado en la Colonia del Viso, que familiarmente mencionábamos como «Rancho».

La estructura de "Conde» creció rápidamente, con el deseo de dar respuesta inmediata a las esperanzas que se habían puesto en tal dispositivo antisubversivo. Así su plantilla de personal pasó de contar con unos pocos Oficiales incorporados en el último trimestre de 1968, a varias decenas sólo dos años después. Gracias a una esmerada selección, pronto se logró constituir un equipo sólido de elevada calidad y prestigio, en que la mayoría de sus componentes estaban en posesión de diplomas de Estado Mayor, carreras universitarias, idiomas, especialidades de criptografía, informática, sociología, etc... a más de las indispensables cualidades personales de liderazgo, afán de superación, deseo de mayor dedicación, inquietudes por el futuro de España, etc... El Ministro del Ejército y el Jefe del Alto Estado Mayor llegaron a decir al Tcol. San Martín que "se había llevado lo mejor de lo mejor», si bien éste redujera la expresión a «lo mejor disponible». La Organización pudo haberse nutrido a base de personal civil para esa comisión de servicio, pero la Superioridad debió confiar más en el oficio secreto de los militares, que quedaron destinados en el AEM -fundamentalmente- y en los EE.MM de los Ejércitos, fórmula que no complacía a dichos organismos militares, y de la que insistieron en desvincularse.

La primera fase de "Conde» aún transcurre en el Ministerio de Educación y Ciencia en razón de las misiones que le habían sido encomendadas de estudio y seguimiento de la subversión universitaria. Pero pronto las autoridades departamentales se verían desbordadas por la cuantía de asuntos que les planteaban los directivos, y que el ministerio empezaba 


\section{Los Servicios de Inteligencia en la Transición}

a considerar superaban su propia competencia. Como el ministro de la Gobernación había pedido a Franco la tutela de «Conde», la Superioridad entendió que la ejecución de las acciones contrasubversivas que proponía la Organización, con el visto bueno de Presidencia, tendría mayor eficacia si se planteaban en coordinación estrecha con los organismos responsables de la seguridad y el orden público. De modo que se creó un Gabinete de Enlace que funcionó a satisfacción de las partes.

A finales de 1970 se organizó en ese Ministerio, como apoyo, un «Gabinete de Acción Psicológica» y en el de Información y Turismo un «Gabinete de pensamiento», según denominaciones al uso de la época. La denominación "Conde» siguió aún empleándose al menos hasta 1976 en conversaciones y relaciones en ámbitos de información y castrenses, a pesar de que tal apelativo nunca tuviera carácter oficial público. En círculos más reducidos de la Administración del Estado también se le seguía conociendo como «Equipo San Martín».

\subsection{La Organización Contrasubversiva Nacional (OCN)}

En febrero de 1971, cuando la Organización «Conde» empezaba a consolidar su red periférica inicial, la Presidencia del Gobierno aceptó su propuesta de plasmar en una Orden Secreta la creación de la Organización Contrasubersiva Nacional con misiones que no eran sino las ya encomendadas a "Conde», ampliadas a otros sectores de actividad nacional en los que se detectaban ya síntomas claros de agravamiento de la tensión frente al Régimen, con exigencias radicales. Tal amplitud de misiones y la urgencia de actuar en áreas civiles tan dispares, para la obtención de noticias, procesamiento de la información y la conveniente acción psicológica, llevaron a condensar los objetivos en unas líneas de acción de lucha contra la subversión, que lograron el refrendo del Vicepresidente del Gobierno, si bien quedando bajo la dependencia operativa del Subsecretario de Gobernación.

Durante algún tiempo las decisiones de la OCN se plantearon en frecuentes reuniones de su Jefe y colaboradores más inmediatos con el Subsecretario Cruylles. Pero el cariz que tomaban aquellas sesiones se iban alejando del espíritu fundacional, pues el Ministerio deseaba hacer uso de tan extraordinaria y peculiar herramienta, como si se tratase de cualquier otro Servicio o Cuerpo departamental, para afrontar sus propios problemas de política gubernativa, lo que atentaba a los planteamientos y objetivos de la Organización. 
En esta fase, la OCN absorbería el "Gabinete de pensamiento», ampliaría sus actividades a los sectores sindical y religioso-intelectual y en marzo redactó un informe de situación sobre la subversión en España que daría pie al «Libro Rojo de la Subversión», completado en junio y difundido en octubre de 1971, que ocasionaría a San Martín no pocos disgustos pues algunas autoridades nacionales empezaban a considerar incómoda -cuando no conflictiva- aquella OCN. De ahí que desde Gobernación y la Secretaría General del Movimiento se pretendiera resolver la situación proponiendo a final de noviembre el nombramiento de San Martín para Gobernador Civil de Guipúzcoa, y buscando para la OCN otro Jefe menos «independiente» di gamos, con menos personalidad. Pero, en vísperas del Consejo de Ministros que debía aprobarlo en la primera semana de diciembre de 1971, la maniobra fue abortada gracias a la información que se hizo llegar con toda urgencia desde la Organización al Almirante Carrero y al TG. Díez-Alegría.

La OCN inicia entonces una nueva fase bajo la tutela de Presidencia del Gobierno, en la que se preparan los textos que harían posible poco después la creación del Servicio Central de Documentación. El 12 de enero de 1972 el Tcol. San Martín despachaba con el Almirante el posible deslinde de la Organización, haciendo radicar la parte oculta en el ministerio de la Gobernación y la más abierta en Presidencia. Sin embargo, una semana más tarde, el Generalísimo decidiría la creación de un Servicio, cuya formulación jurídico-administrativa vendría a proteger las actividades de la OCN desde la Presidencia del Gobierno.

En marzo de 1972, tras la creación del SECED, se revisaría el texto de la Orden Secreta de la OCN para adaptarla a la realidad del nuevo Servicio. Aún transcurrirían otros tres años para que el Presidente Arias firmase en febrero de 1975 una nueva Orden Secreta, que actualizaba la anterior, a la vista del crecimiento de la OCN y de la situación nacional. La Organización Contrasubersiva Nacional se fue disolviendo como tal dentro del SECED hasta que desapareció sin derogación alguna al constituirse el CESID en 1977. Pero, a efectos del presente trabajo, ponemos fin a la época de la OCN, en el mismo momento en que comienza la andadura del SECED, pese a que aquella Organización Contrasubversiva, como decimos, pervivió unos años como rama clandestina, fundamento del Servicio.

\section{El Servicio Central de Documentación (SECED)}

La creación de este importante e interesante Servicio de Información merece una exposición detenida. El denso contenido de sus misiones y la 


\section{Los Servicios de Inteligencia en la Transición}

enorme actividad desplegada a lo largo de los seis años de su existencia hace conveniente subdividir ese tiempo en tres bienios en los que aparecen tres Directores diferentes -los tres, Tenientes Coroneles del Ejército- subordinados a tres sucesivos Presidentes del Gobierno. Bien podríamos denominar, de entrada, esas etapas como de creación, expansión y consolidación del Servicio, fortalecimiento que quedaría definitivamente rematado con la constitución en julio de 1977 del Centro Superior de Información de la Defensa (CESID).

\subsection{La etapa de creación. Bienio Carrero/San Martín (1972-73)}

El SECED se crea por Decreto de la Presidencia del Gobierno el 3 de marzo de 1972, para dar a la OCN la cobertura oficial y estable que necesitaba, lo cual aconsejaba su incardinación en Presidencia con una nueva fachada al exterior. Las numerosas relaciones institucionales iniciadas por la Organización debían consolidarse y multiplicarse, lo que exigía una nueva vía de encuentro totalmente abierta, no imaginable -por innecesaria- en los primeros tiempos de la OCN. Para ello se decidió montar la sede del SECED en la Calle Alcalá Galiano, $\mathrm{n}^{\circ} 10$, inmediata a la Presidencia del Gobierno, al tiempo que se ampliaban y reforzaban las oficinas de los Sectores de la OCN en otros inmuebles de Madrid en los que se mantenía de algún modo su carácter clandestino.

Así el nuevo Servicio recibió una articulación orgánica con la que atender de forma pública a las necesidades administrativas y políticas de la OCN, así como a la adecuada coordinación de la labor de sus Sectores centrales y Delegaciones territoriales, que conservaban en plenitud sus misiones secretas y actividades clandestinas para hacer frente a la lucha contra la subversión. El Servicio quedaría integrado por las Secciones de Régimen Interior, Estudios e Informes, y Coordinación y Enlace. La dependencia que se fijaba para el SECED respecto del Vicepresidente del Gobierno -un año más tarde, ya Presidente- imprimía un carácter a este Servicio, que aseguraba la estrecha vinculación inicial de «Conde» al Almirante Carrero. San Martín sería nombrado Jefe del SECED con categoría de Director General, lo cual le facilitaría el trato habitual con otras autoridades.

La proximidad física, afectiva y leal de San Martín al Almirante Carrero y la fluidez de sus relaciones oficiales con él, así como el prestigio adquirido por la OCN y su indiscutida influencia en diversas áreas de poder, habían producido algunas envidias y no pocos recelos de dirigentes de otros Servicios que se sentían postergados a la hora de imponer sus 
propias apreciaciones y de conseguir recursos económicos y facilidades que creían se daban a aquella Organización.

Las necesidades informativas y de asesoramiento sobre variados temas nacionales relacionados con la economía, la reorganización de la Administración, la proyección política de la legislación, etc. obligaron a incrementar e institucionalizar la ejecución de numerosas entrevistas con una variadísima gama de autoridades públicas y personalidades de los más diversos ámbitos, mediante las cuales perfeccionar la toma de conciencia de las verdaderas preocupaciones de la sociedad. Este medio de adquisición de información privilegiada amplió sustancialmente el banco de datos del Servicio, poniendo a disposición del Vicepresidente una novedosa y ágil vía de conocimientos de distintos aspectos y enfoques, tanto del estado de la nación como de los miembros más relevantes de cada sector social de influencia. Tal procedimiento se extendió con gran rendimiento informativo a las Delegaciones y Subdelegaciones que se iban abriendo en capitales que o bien eran cabeceras de Región Militar o merecían el mayor interés a los fines del Servicio. Igualmente se extendió la labor de las Oficinas de Enlace abiertas en un buen número de ministerios civiles, cuya oficialización permitió consolidar el flujo informativo y su rigor, acomodándose su funcionamiento a la nueva realidad del Servicio.

La mayor generosidad con que se ponían a disposición del SECED los recursos de todo tipo produjeron pronto un incremento sustancial de la plantilla de personal, aún constituida casi en su totalidad por miembros de las Fuerzas Armadas y de los Cuerpos de Seguridad del Estado y recurriendo a la fórmula de jornada de tarde cuando resultaba ya imposible incorporar personal fijo. Pero ese aumento de plantilla en la que se apoyaba la creciente labor en la OCN, chocaba con los organismos que tenían que facilitar el personal. Como ejemplo más claro, el Alto Estado Mayor aceptaba a regañadientes tener allí destinados a la mayor parte de los Oficiales de la OCN pues no podía ejercer control sobre ellos ni librarse de presumibles implicaciones que determinadas actuaciones clandestinas pudieran empañar la imagen del alto Centro. La verdad es que su Tercera Sección echaba de menos contar con un plantel tan numeroso y cualificado, con el que ella hubiera podido desarrollar idénticas misiones desde Vitruvio. Al propio tiempo las más abundantes dotaciones presupuestarias se tradujeron en la adquisición en nuevos medios técnicos de recogida de información, de transmisión y de archivo, que sirvieron de ejemplo a seguir por otros Servicios.

Por entonces aceleró el Alto Estado Mayor los deseos de fijar límites de competencia entre su Tercera Sección y el Servicio de Presidencia, en 


\section{Los Servicios de Inteligencia en la Transición}

lo referente a la lucha contra la subversión y a los apoyos informativos en el extranjero, aunque la personalidad de San Martín no resultaba particularmente cómoda para algunos de sus interlocutores, pues -según se decía- no era hombre fácil de avasallar. No obstante se dieron pasos importantes y las relaciones Vitruvio-Alcalá Galiano se hicieron más fluidas, estableciéndose cauces para el estudio de un posible Servicio de Inteligencia para las Fuerzas Armadas, vinculado al Alto Estado Mayor.

La época "San Martín» concluiría tras el asesinato del Almirante Carrero Blanco el 20 de diciembre de 1973 a manos de la banda terrorista ETA, terminando así cinco años de absoluta e intensa dedicación personal, suya y de sus colaboradores, a la creación de una máquina informativa, básica en el intento de apoyar eficazmente al Estado. A su tesón se debe la puesta en marcha de unos equipos, un estilo y empuje que poco tenían que envidiar a los Servicios precedentes. Pero los medios de que dispuso, las facilidades de acceso a la clase dirigente y no pocos éxitos, produjeron -como indicábamos antes- todo tipo de celotipias y envidias entre quienes veían que el SECED y su control se les escapaba definitivamente de las manos, en un despegue que se presumía acelerado.

A la OCN se le achacó insidiosamente no haber detectado la preparación del atentado terrorista contra el Presidente Carrero, pues ya correspondía a la Organización el estudio y seguimiento de la subversión, que incluía obviamente a las bandas terroristas. El Servicio había dado pasos firmes en la evaluación de esa amenaza interior e incluso en la infiltración de sus estructuras; pero se trataba de una tarea recientemente asumida que requería de muchos años para alcanzar el ambicionado nivel de eficacia. Por el contrario, en algunos sectores sorprendería el acceso a la Presidencia del Gobierno de quien fuera ministro de la Gobernación en el momento del magnicidio. Tampoco sus órganos de información y seguridad habían podido evitarlo.

Terminaba así el primer bienio del SECED, lleno de ilusión y aventura, rompiendo moldes, soñando un futuro mejor, pero -es verdad-con un crecimiento desigual en sus articulaciones y extremidades, como ocurre en todo cuerpo humano en el paso desde la niñez a la adolescencia. El Servicio entraba en otra etapa.

\subsection{La etapa de expansión. Bienio Arias/Valverde (1974-75)}

El nombramiento de Arias Navarro como Presidente del Gobierno a punto de finalizar el año 1974 traería como consecuencia el relevo en la 
dirección del SECED, que pasó a manos del Comandante Valverde Díaz, algo más moderno y joven que San Martín, aunque con escasos conocimientos del proceloso mar de los Servicios de Información, lo que le aconsejó apoyarse en los órganos directivos del Servicio y llevar el timón de la OCN con un estilo menos personalista que su predecesor y más acomodado a las circunstancias reales en que se debatía la política nacional tras el asesinato del Almirante.

El nuevo Director había accedido al cargo por decisión personal de Arias Navarro, quien siendo Alcalde de Madrid había nombrado Gerente Municipal de Urbanismo, al entonces Capitán Valverde. Esta amistosa proximidad al Presidente coadyuvó en gran medida a salvar las dificultades políticas y administrativas que habían enturbiado en ocasiones la buena marcha y desarrollo del Servicio en su primera fase.

Las cualidades personales de Valverde -tacto, bonomía, prudenciafacilitaron enseguida sus relaciones de mando con los directivos del SE$\mathrm{CED}$, de los que recogió sugerencias y sentimientos para reorientar el rumbo de la nave ante la nueva situación. Después de escuchar a todos, dio pronto un golpe de timón que impulsó al Servicio hacia el estudio profundo, el planteamiento y seguimiento de acciones fundamentalmente orientadas a la reversión y a facilitar al Presidente del Gobierno una información puntual, completa y rigurosa de los asuntos nacionales encomendados.

La articulación interna del SECED/OCN fue actualizada según el nuevo concepto que habría de corresponder al Servicio, concentrando todos los órganos en dos Divisiones (Operaciones e Información) y una Secretaría General que atendía a todos los asuntos de personal, administración, servicios, etc... Valverde había rechazado firmemente desde el

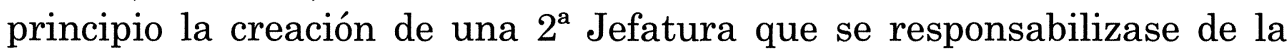
OCN, como organización con cierta independencia del Director. Fue así sumida en el conjunto del Servicio, desapareciendo poco a poco el uso habitual de las siglas OCN; no de sus cometidos, naturalmente. Como el rápido crecimiento vital del SECED no había concedido tiempo durante la primera fase para consolidar un fondo de doctrina y un estilo de funcionamiento, pues los cambios habían ido siempre por delante de las disposiciones que habrían de respaldarlo, ahora era el momento de adentrarse en esa laboriosa tarea.

Con carácter general puede decirse que en esta segunda etapa del SE CED se institucionalizó el proceso de la información en los diferentes ámbitos del Servicio, así como los canales de relación con las autoridades civiles y militares. Se logró implantar un procedimiento uniforme tanto en 
la adquisición de noticias, su evaluación y contraste, como en la elaboración de "inteligencia» y su conveniente difusión. Destaca en esta segunda fase la expansión de las fuentes de información, en particular el fuerte aumento de entrevistas, que multiplicaron exponencialmente la información recogida.

La plantilla de personal creció sustancialmente en estos dos años y medio, bajo el Presidente Arias, manteniéndose la elevada cualificación de los directivos del SECED. La Oficialidad continuaba con la ilusión y espíritu inicial, pero se iban imponiendo los relevos, por el deseo de algunos de incorporarse de nuevo a un destino en los Ejércitos, al sentir ya la fatiga de un esfuerzo continuado en la lucha contra la subversión. Unos se lamentaban de la desconfianza hacia el Servicio -incluso hostilidad-observada en otras instituciones de las que cabría esperar pleno apoyo; otros no entendieron quizá los nuevos aires que circulaban por la "Casa", recordando con nostalgia aquellos primeros años en los que un fuerte componente de espíritu juvenil e inquieto creaba métodos de acción, más que de estudio, para salvar un ambiente nacional que se deterioraba a paso agigantado.

Se revisaron también las Delegaciones territoriales y las Oficinas de Enlace en ministerios civiles, para adecuarlas a las nuevas necesidades, al tiempo que la sede central del Servicio se trasladaba desde el piso de Alcalá Galiano, 10, hasta el edificio del Paseo de la Castellana ${ }^{\circ} 5$, ocupado desde su construcción por la Dirección General de Marruecos y Colonias -en esta etapa, de Plazas y Provincias Africanas- donde ya se pudo acoplar el SECED con decoro y sin estrecheces en instalaciones y servicios, albergando dignas salas de reunión y de visitas como correspondían a un organismo público abierto que requería una imagen, más cercana y acaso menos críptica. Se montó adecuadamente el archivo mecanizado de información -el ya afamado "JANO»- y pudo darse cobijo a alguna de las oficinas que aún se mantenían fuera de este edificio principal.

En la vida política nacional, los deseos de apertura de unos chocaban con los temores de derrumbamiento del Sistema, de otros. Al programa del notorio «espíritu del 12 de febrero», expuesto en las Cortes Españolas por el Presidente Arias, se sucedieron numerosos episodios como el llamado "gironazo" y otros, que mostraban la cara más lamentable de las discrepancias entre fracciones que a lo largo de decenios habían constituido el firme basamento del Régimen, apoyado en los Principios Nacionales del Movimiento. El SECED, sin desatender su propia labor contrasubversiva, prestó, particular atención a observar y evaluar las actitudes 
de los grupos políticos que deseaban hacerse hueco para participar en la imparable transición que se avecinaba: la izquierda más moderada ya empezaba a salir de la clandestinidad.

En esta segunda fase del SECED se ponen en marcha varias operaciones de carácter nacional, tratando de adivinar y prevenir posibles situaciones críticas cuando se cumpliesen las «previsiones sucesorias», eufemismo con el que se evitaba citar el fallecimiento del Caudillo. La Operación «Lucero», dirigida por el propio Presidente del Gobierno, pero desarrollada por el Servicio, estudió en detalle y coordinó las numerosas y complejas acciones para que la noticia del óbito del Jefe del Estado no ocasionara, en su momento, alteraciones de orden público incontrolables e irreversibles, y que las medidas previstas para el momento del tránsito político pudieran ser aplicadas en un clima pacífico y democrático. Esta operación se complementaba con la «Alborada», referida a los primeros actos institucionales de la Monarquía; la «Relámpago», que afectaba en exclusiva al ámbito del SECED; y otras de diversos organismos, como Gobernación, ministerios militares y Alto Estado Mayor que pusieron al día las medidas pertinentes de seguridad, coordinadas -eso sídesde Presidencia. La esmerada preparación de aquellas Operaciones hicieron viable la transición pacífica, que sorprendió a muchos y que en adelante se ofrecería como ejemplo para otras naciones.

Arias continuó al frente del primer Gobierno de la Monarquía y, con él, el Teniente Coronel Valverde como Director del SECED. Los movimientos políticos agudizaron su actividad y sus líderes se esforzaron por tomar parte en el nuevo panorama que se abría. Resultó un tiempo bien aprovechado por el Servicio para fortalecer su espíritu y su estructura interna. Iba a dar comienzo la tercera fase, última de la vida del SECED.

\subsection{La etapa de consolidación. Bienio Suárez/Cassinello (1976-77)}

La decisión de SM el Rey de sustituir al Presidente Arias por Adolfo Suárez al frente del Gobierno supuso también el relevo de Valverde por el Teniente Coronel Andrés Cassinello, quien venía desempeñando la Jefatura de la División de Operaciones del SECED y anteriormente otros puestos de destacada responsabilidad con San Martín. Su profundo conocimiento del Servicio y su personal y definitiva influencia en la transformación del SECED durante la etapa Valverde dio continuidad a las disposiciones que se habían venido adoptando en los años anteriores, sin que el cambio de Gobierno supusiera un parón -mucho menos un retor- 


\section{Los Servicios de Inteligencia en la Transición}

no- en cuanto se había avanzado. De modo que las reconocidas dotes intelectuales y capacidad de mando del nuevo Director le hicieron el hombre idóneo para gobernar la nave del Servicio en una fase crucial en la que habría de materializarse la transición política española.

$\mathrm{Al}$ igual que los dos directores que le precedieron, supo infundir al SECED su estilo personal, como convenía a esta tercera fase -la de consolidación- en la que el Servicio fue aplicando fórmulas y procedimientos, sustentados por propuestas y acciones de órganos muy especializados que daban a su trabajo un tono cada vez más profesional y riguroso. Por otra parte, a medida que la vía democrática se iba abriendo paso en las instituciones, se ensanchaba la banda de necesidades de "inteligencia» a requerimiento de Presidencia y perdían peso algunas facetas contra-subversivas del SECED, al desaparecer razones esgrimidas por grupos antiRégimen para justificar sus revueltas y enfrentamientos.

La confección de Planes de Información y de Programas de Investigación fue ya una práctica habitual en el SECED, como normas orientadoras de la actividad profesional del Servicio. El trabajo de Directivos, Ayudantes y Auxiliares encontró su ritmo y su eficacia con regularidad, sin los sobresaltos que surgían con más o menos frecuencia en las etapas anteriores. Puede asegurarse que el SECED se consolidó como un Servicio competente y de alto rendimiento, y que su apoyo informativo al Presidente del Gobierno y a SM el Rey, dio la medida de un trabajo riguroso y moderno que se ofrecía por medio de informes y boletines periódicos, cuya difusión se extendió en esa etapa a otras autoridades militares y civiles.

Afortunadamente -como ocurriera en el tandem Arias/ValverdeCassinello era conocido por Suárez en ámbitos familiares desde años antes, circunstancia que favoreció la relación de confianza y con ella la fluidez de despacho frecuente con el Presidente del Gobierno. La atención continuada y exhaustiva de Suárez a los problemas que suponía el cambio político emprendido, dejó suficiente libertad de acción a Cassinello para continuar con el desarrollo de sus planes de transformación del Servicio y consolidar la tarea encomendada a los Sectores Centrales y a la estructura periférica del SECED, a los que pudieron aplicarse nuevos recursos humanos y financieros.

La tensa y acelerada situación nacional por cuanto suponía la Reforma Política y la aprobación de asociaciones y partidos haría conveniente la profundización por parte del SECED en la información sobre movimientos de grupos y personas en relación con decisiones gubernamentales que trataban de afrontar la nueva etapa democrática con vistas al re- 
feréndum, elecciones generales, futura Constitución, etc..., lo que no supuso -por fortuna - una politización de la «Casa» sino más bien la asunción de un papel de Estado que diferenciaba la acción del Gobierno Suárez de la correspondiente al partido político que le sustentaba, entonces la Unión de Centro Democrático (UCD). El Servicio colaboró a fondo con el Presidente del Gobierno en el conocimiento de los grupos que iban a saltar a la arena democrática, y en el asesoramiento leal sobre cuantos criterios se recogían en numerosísimas entrevistas concertadas por directivos del SECED con personalidades de todos los sectores de la vida nacional. Este apartidismo necesario ocasionó serios disgustos al TCol. Cassinello con el Presidente Suárez y otros miembros del Gobierno, quie nes exigían una cooperación más amplia y profunda en toda la preparación electoral.

Hay que recordar que el crecimiento de la OCN y del SECED se había llevado a efecto en años anteriores con gran identificación política respecto de los sucesivos Gobiernos de la Nación, convirtiéndose el Servicio en un utensilio extraordinario e irrenunciable, en manos de sus Presidentes, que lo usaban con gran celo. Pero con la instauración del régimen parlamentario, el Servicio tenía que desligarse de lo puramente coyuntural y partidista, para concentrarse en objetivos nacionales del Estado. No siempre se lograría, pero sí se afianzaron las bases para que el futuro CESID pudiera establecerse institucionalmente como un Servicio apartidista.

En la última etapa del SECED merece reseñarse el enorme esfuerzo desarrollado por continuar la lucha contra el terrorismo, en la que jamás se regatearon esfuerzos y en la que se lograron importantes avances -incluso éxitos- que nunca transcenderían al conocimiento público. Asimismo cabe reseñar la gestión personal de Cassinello para hacer realidad el regreso de Tarradellas a Cataluña, donde tiempo después sería designado President de la Generalitat.

Esta tercera fase se cierra naturalmente con los intentos de coordinación de los Servicios de Información ya iniciados durante el mandato de Valverde, y que se reactivaron de la mano del Teniente General Gutiérrez Mellado, Vicepresidente del Gobierno para Asuntos de la Defensa estableciéndose puntos de encuentro, pese a las dificultades que presentaban los organismos a coordinar y que finalmente encontrarían solución tras la creación del CESID en julio de 1977. El Servicio prestó todo el apoyo a su integración con la Tercera Sección del Alto Estado Mayor, cuyo estudio meditado y exhaustivo hizo posible la aparición del primer Servicio de Inteligencia nacional con todos los elementos indispensables 


\section{Los Servicios de Inteligencia en la Transición}

para ser considerado como tal en las naciones de corte occidental. La operación de fusión se vió facilitada por el hecho de que ambos organismos dependieran de la Presidencia del Gobierno y estuviesen servidos por profesionales de las Fuerzas Armadas.

\section{El fin del SECED}

Acababa así un proceso iniciado impensadamente con la Organización "Conde» en otoño de 1968, con aportaciones sucesivas a lo largo de nueve años y bajo la dirección de tres Tenientes Coroneles, con plantillas de Jefes y Oficiales más modernos y jóvenes que ellos mismos, lo que daba al Servicio una imagen y un estilo cargados de un empuje excepcional, a veces trufado de actuaciones menos prudentes, como cabe suponer de gentes que apenas superaban los 40 años de edad. El nivel de ese empleo militar debió parecer a algunos políticos y mandos castrenses insuficiente para manejar una herramienta tan compleja y de uso tan difícil y peligroso, por lo que el nuevo bisturí -el CESID- se puso en manos de Oficiales Generales y Coroneles. Pasarían unos años más, hasta que inopinadamente volvió a encomendarse la dirección a un Teniente Coronel, que ascendería sucesivamente en ese puesto hasta alcanzar el rango de Teniente General.

Ya hemos referido cómo el estilo personal de San Martín, Valverde y Cassinello y la enorme influencia política del SECED habían originado no pocos recelos y envidias en los restantes servicios y órganos de información entre quienes parecía tenían el deber de apoyarles. Quizá el SECED debió hacerse perdonar tan favorable posición; acaso no supo hacerlo a satisfacción de sus oponentes. De modo que el distanciamiento entre Servicios afines dificultó la deseable coordinación e incluso el intercambio de información y de inteligencia, que no fue realidad hasta consumarse la creación del CESID como Servicio único de nivel nacional.

Ya el primer Gobierno de la Monarquía y sobre todo el segundo tomaron conciencia de las ventajas de concentrar los ministerios militares en un nuevo Departamento de Defensa, apareciendo como insuficiente la figura de un Vicepresidente coordinador de tales asuntos. Los deseos de cambio que se plasmarían en la reforma política y en la nueva Constitución alcanzarían también el ámbito de las Fuerzas Armadas con la vista puesta en un solo ministerio que agrupase a los tres departamentos militares. Tan imparable concentración -resuelta desde hacía décadas en 
otros países occidentales- llevaba implícita la reunión de los órganos de Inteligencia nacional en una sola mano y los de Información militar en otra. Se barajaron fórmulas posibles y se hicieron propuestas muy diversas que dieron pronto luz al CESID, como nuevo Servicio Nacional de Inteligencia, tarea en la que colaboró intensamente el SECED, como hemos apuntado.

El buen ritmo aplicado al estudio de la creación del CESID se debió sin duda a la constatación de las ventajas que aportaban la Tercera Sección AEM y el SECED: sus correspondientes misiones reservadas, su prestigio indiscutido, su personal especializado, instalaciones y equipamiento sofisticado. Pero no es menos cierto que también se intuía la fusión como ocasión propicia para resolver algunas deficiencias en sus respectivas estructuras y funcionamiento. Al decaimiento del Alto Estado Mayor en influencia y eficacia, se unía por otra parte la sospecha de que el SECED actuaba sin suficiente control desde Presidencia del Gobierno.

Pronto el CESID pasaría a depender del nuevo Ministerio de Defensa, por el carácter militar de la inmensa mayoría de sus componentes y quizá por entender como políticamente ventajoso colocarle al Presidente del Gobierno una pantalla intermedia que le alejara y protegiera de posible fallos o errores del Servicio, aunque el CESID resultaría algo así como un traje del Jefe del Ejecutivo, guardado en el ropero de Defensa. De hecho la adscripción tenía un carácter administrativo más que directivo: los grandes asuntos de Inteligencia se seguirían planteando en La Moncloa más que en el Paseo de la Castellana.

Es de justicia citar al final de este capítulo la inmensa y callada aportación del SECED a la lucha contra el terrorismo. La necesaria discreción de cuantos participaron en multitud de estudios y asesoramientos a los poderes públicos para orientar adecuadamente la acción de los Tribunales y las Fuerzas de Seguridad del Estado, impide desarrollar aquí mínimamente situaciones y logros que unos pocos podrían relatar en muchas páginas. Pero al menos, aquéllos que arriesgaron incluso su vida como miembros de su Servicio de Inteligencia y como militares que eran, merecen nuestro recuerdo agradecido.

Quedaban atrás años de sacrificio e ilusión, de numerosos aciertos y algunos errores, como en toda obra humana. Pero bien puede decirse que la Transición no hubiera sido la misma sin esa cardinal aportación -indispensable habría que decir-. De alguna manera aquel tránsito político debe una parte fundamental a la abnegada labor de la OCN/SECED. 


\section{Epílogo}

$\mathrm{Al}$ concluir este breve trabajo sobre los Servicios de Inteligencia durante el periodo de mutación política, cabe resumir que ese decenio que abarca desde el otoño de 1969 hasta el otoño de 1978, fue vital para los Servicios tanto como para la Transición. Ni el tránsito a la democracia hubiera podido resultar exitoso sin los Servicios, ni éstos se hubieran desarrollado como convenía sino se hubiera producido la Transición. Los directivos de los Servicios de Inteligencia sintieron los aires nuevos que se avecinaban y forzaron en cada momento cambios que eran indispensables. Por su parte, los políticos escucharon a los Servicios y pudieron plantear sus proyectos democráticos con prudencia y dentro de un marco que hubiera sido altamente peligroso sobrepasar. De ese modo se llegó a la aprobación muy mayoritaria de una nueva Constitución Española y se instituyó el primer Gobierno de la Nación surgido de unas Cortes Generales plenamente democráticas. Lo que hubiera resultado casi un sueño pocos años antes se lograba con la colaboración y el aplauso de la inmensa mayoría de los españoles. Se había salvado, en un clima de paz y sosiego, el paso de un Régimen autoritario y personal a una Monarquía parlamentaria de corte europeo. La maquinaria política estaba en marcha. Tan sólo quedaría ponerla a punto en los años siguientes. Exactamente igual que ocurriría con la Inteligencia.

De ese modo podemos asegurar que esos años de los Servicios de Inteligencia fueron cruciales para la germinación y desarrollo inicial de un organismo adecuado a las nuevas y futuras necesidades nacionales. Veinticinco años de funcionamiento del CESID abocarían en un definitivo Centro Nacional de Inteligencia, con todas las connotaciones de los principales servicios extranjeros, entre los que el nuestro bien puede ya estar considerado como uno de los primeros del mundo. 